\title{
A review of literature on benefits of taper phase for main competition of periodization model in endurance athletes
}

\author{
Jae-Ryang Yoon* \\ Korea National Sport University
}

\begin{abstract}
[Purpose] The aim of this study was to provide athletes and coaches on informations and benefits of a taper through evidence-based scientific studies and literatures in order to optimize an athlete's top performance for the major competition. [Methods] Studies and literatures search was conducted using the databases RISS, KISS, SPORTDiscuss. Key words searched: taper AND(competition, OR performance, OR training, OR training). This study were eventually cited by 22 articles for results of this in total 100 articles. [Results] The training load is remarkably reduced during a taper. With a reduced training load, training intensity should be maintained during the taper. The training load reductions during the taper should be programmed with reducing training volume at $41 \%$ to $60 \%$ of pretaper training. The reduction of training frequency during a taper means that affect moderately trained athletes and highly trained subjects differently, reducing $30 \%$ to $50 \%$ of pretaper training and maintaining training frequencies, respectively. Detraining the duration of a taper is not easy. Most athletes is beneficial from a 2-week shorter or longer tapers, depending on their individual profiles of fitness loss, fatigue dissipation, and anxiety. The manipulations of this training program variables usually affect for most athletes and maximal performance gains. [Conclusion] Training intensity should be maintained during the taper, training volume reductions should be programmed at $41 \%$ to $60 \%$ of pretaper training. The reduction of training frequency could be reduced $30 \%$ to $50 \%$ of pretaper training, and most athletes is beneficial from a 2-week shorter or longer tapers. Future researches should be conducted the practical \& effectual differences in individual and teamed-based sports after a taper procedure.
\end{abstract}

Key words: taper, training load, training variables, reduced training, performance

\section{서 론 \\ 모든 스포츠종목의 지도자들에게 가장 중요한 목표는 자기가 지도하는 선수의 경기력을 높이는 것이다. 그 동 안 많은 스포츠지도자들은 선수의 경기력을 높이기 위해 과학적이고 체계적인 방법으로 훈련을 지도해 오면서 스}

논문 투고일 : 2020. 09. 21.

논문 수정일 : 2020. 11. 02.

게재 확정일 : 2020. 12. 03.

* 교신저자 : 윤재량(jryoon@knsu.ac.kr).
포츠 선진국의 과학적인 트레이닝방법에 대한 관심이 높 아지면서 많은 종목에서 주기화 개념에 의한 트레이닝의 중요성이 강조되고 있다. 주기화란 트레이닝의 효과를 최 적화하기 위해 일정기간을 관리하기 쉬운 더 작은 단위의 기간으로 나누어 주요 시합에서 최고의 경기력을 발휘하 기 위해 트레이닝 프로그램을 과학적으로 세분화하는 과 정이다(Bompa \& Carrera, 2005; Bompa \& Haff, 2009; korean Society Of Exercise Physiology, 2018). 그러한 연간계획을 세분화하는 과정에서 주시합 
기(main competition) 중에서도 시합직전의 단계를 무 부하기(unloading phases=tapering)이라 부른다 (Hoffman, 2014). 본래 테이퍼링 (tapering)이란 경제 학에서 사전적 의미로 사용된 용어로 "자산매입 규모를 줄여나간다는 의미로 양적완화, 규모축소라는 뜻이지만, 스포츠트레이닝에서는 오버트레이닝에 의한 상해, 부상 의 위험 가능성을 최소화한다는 뜻으로 "마라톤, 수영선 수 등 지구력선수들의 중요시합을 앞두고 훈련량을 점차 줄여나가는 과정이라고 하였다"(Hoffman, 2014; De Lacey et al., 2014). Matveyev's 주기화 모델에 따르 면, 이러한 테이퍼링은 연간훈련 계획 중 전반적인 훈련 량 증가 이후 중주기(mesocycles)의 마지막 단계 (peaking phase)으로서 훈련량을 줄이고 훈련강도는 증 가시켜 중요시합에서 최상의 컨디션을 최고(peaking)의 경기력을 유지할 수 있도록 하는 국면을 말한다 (Hoffman, 2014; Bosquet et al., 2007; Mujika et al., 2000). 테이퍼링은 운동선수가 시합을 대비할 목적 으로 근력 및 컨디셔닝 조절 전반에 걸쳐 널리 사용되는 일반적인 방법이며(Mujika \& Padilla, 2000; Shepley et al., 1992), 또한 테이퍼링은 지구력이 필요한 선수들 이 중요한 시합을 앞두고 훈련량을 점차적으로 줄여나가 는 과정이라고 하였다(Mujika \& Padilla, 2003; Mujika, 2011 ). 동시에 테이퍼링은 경기력향상에 대한 기대치의 부정적인 영향과 긍정적인 영향의 적절한 균형 을 통해 최적의 경기력을 달성하려고 시도하는 것이다. 이러한 시합전 훈련량에 대한 생각은 경기를 앞둔 시전까 지 많은 양의 강도 높은 트레이닝을 실행하도록 만드는 원인이지만 시합에 대한 체계작인 훈련량 감소는 오히려 선수들의 경기력에 긍정적인 결과를 가져다 줄 수 있다고 하였다(Park \& Jang, 2014; André, Anton, \& Yu, 2013; Lee, 1998). 이와 관련하여, 선행연구들은 훈련 강도, 훈련량, 훈련빈도, 테이퍼링 지속기간, 그리고 테 이퍼링 유형으로 구성된 생리적 적응 효과에 영향을 미치 는 훈련프로그램 구성요소를 일관되게 확인하여 왔으며, 이와 관련한 문헌연구들은 본 연구에서 충분히 논의되었 다(Bosquet et al., 2007). 테이퍼링에 관한 긍정적 연구 증거가 증가하고 있으며, 훈련강도, 훈련량, 훈련빈도에 대한 이상적인 처방을 제시하는 연구도 있었지만(Jang $\&$ Lee, 2007), 트레이닝 구성요소와 관련한 생리적, 심
리적 성과를 극대화하기 위한 적응과 회복 사이의 최적 균형에 관한 연구결과에서는 여전히 상충되는 연구결과 들도 있다(Houmard et al., 1994; Neary et al., 2003).

따라서, 본 연구에서는 문헌연구를 통해 테이퍼링 방 법이 대체로 중요 시합을 앞둔 상황에서 부정적 효과보다 는 긍정적 효과를 가져온다는 많은 연구결과들이 있음을 조사하고, 동시에 긍정적인 효과가 입증된 경우라도, 그 긍적적인 테이퍼링의 효과적인 방법, 그리고 테이퍼링에 의한 경기력을 최적화하기 위한 방법의 훈련프로그램 구 성요소, 즉 훈련부하 감소방법으로 훈련강도(intensity), 훈련량(volume), 훈련빈도(frequency), 테이퍼의 지속 기간(duration), 그리고 테이퍼링의 유형(type)을 체계 적으로 제시하는데 그 목적이 있다.

\section{연구방법}

본 연구는 지금까지 각 종목 운동선수들의 테이퍼링을 주제로 이루어져 온 연구들을 재검토하는 문헌연구 방식 을 사용하였다. 본 연구에 분석된 자료는 주제와 관련하 여 연구자 본인이 소장하고 있는 자료와 함께, 학술정보 를 검색할 수 있는 검색엔진을 통해 학회지에 투고되거나 출판물로 발간 된 자료를 분석하였으며, 그 과정은 〈Figure 1〉과 같다.

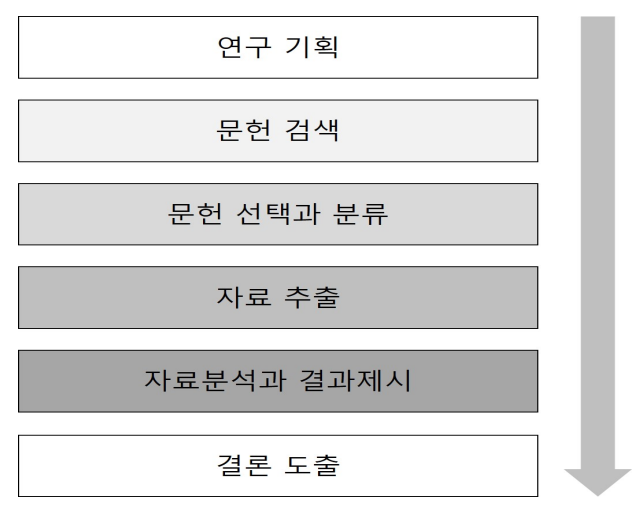

Fig. 1. 문헌고찰 수행 과정 


\section{자료 수집}

본 연구의 검색 기준은 1995 년부터 2020 년까지의 문헌 으로, 국내문헌 자료 수집은 한국체육대학교 학술정보원 (library.knsu.ac.kr)과 한국학술정보서비스(kiss.kstudy. $\mathrm{com})$ 를 통해 수집하였고, 국외문헌 자료 수집은 SPORT Discus를 이용하였다. 국내문헌 검색에서 사용된 검색어 는 '주기화, '주기화 훈련', '테이퍼'이며 국외문헌 검색에 서는 제목과 초록 수준에서 "periodization' 'taper'로 두 단어가 모두 포함된 것으로 한정지어 검색을 실시하였다. 연구서론에서 인용된 문헌을 제외한 자료검색 결과 국내 문헌 37편, 국외문헌 63 편으로 총 100 편을 수집하였다.

\section{문헌 선택과 분류}

문헌 선택과 분류 절차는 〈Figure 2〉와 같다. 문헌 선 별 과정에서는 먼저 중복된 자료를 삭제한 후 제목과 초 록 검토를 실시하였으며, 문헌 분류 기준은 훈련 주기화 이론에 의한 테이퍼링 국면을 사용하고 있는 문헌 중 대 상자가 엘리트선수이어야 하고, 전신지구력 종목을 대상 으로 하며, 적어도 훈련 프로그램 구성 요소 중 하나 이상 의 변수가 포함된 연구 논문을 대상으로 선정하였다. 또 한 가급적 최신의 정보를 제공하기 위해 초기 문헌 검색 에서는 1995년 이후 문헌으로 검색을 실시하였으나 자료 가 다소 미흡할 것으로 판단되어 연구 결과의 질적 향상 을 위해 연구자 본인이 소지하고 있는 자료를 토대로 1995년 이전의 문헌 3편을 추가하여 연구결과에 포함하 였다. 이에 최종적으로 본 연구 목적에 부합하는 문헌 22 편을 선정하여 분석을 실시하였다.

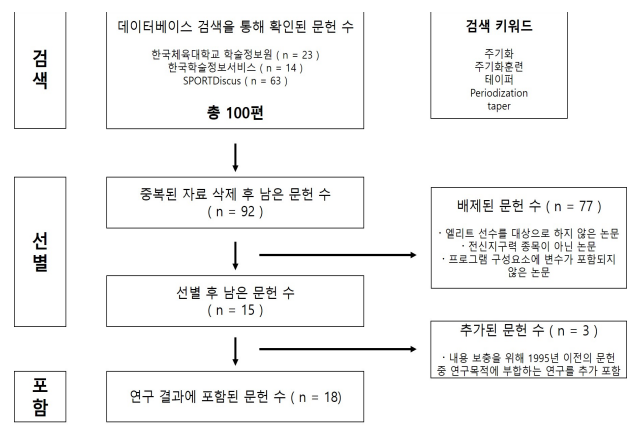

Fig. 2. 문헌 선택과 분류 절차

\section{연구결과}

본 연구는 운동성수가 중요 시합에서 최적의 경기력을 달성하기 위한 목적으로 테이퍼링을 적용하려 할 때, 시 합 시기에 맞춰 최대 경기력 수준을 달성하려는 시도로 훈련프로그램 구성요소를 잘 조절하는 것이 중요하기 때 문에(Bosquet et al., 2007), 테이퍼링에 의한 훈련부하 감소방법으로 훈련강도(intensity), 훈련량(volume), 훈련빈도(frequency), 테이퍼링의 지속기간(duration), 그리고 테이퍼링의 유형 (type)을 선행 연구된 많은 문헌 결과를 통하여 체계적으로 제시하고자 한다. 이를 트레이 닝의 강도, 훈련량, 빈도별 문헌연구의 경기력 분석 결과 를 정리하면 〈Table 1〉과 같다.

Table 1. 트레이닝의 강도, 훈련량, 빈도별 문헌연구의 경기력 분석결과

\begin{tabular}{|c|c|c|c|}
\hline 구분 & 저자 (연도) & 처치 내용 & 경기력 효과 \\
\hline \multirow{4}{*}{$\begin{array}{l}\text { 트레이닝 } \\
\text { 강도 }\end{array}$} & $\begin{array}{l}\text { Shepley et } \\
\text { al.(1992) }\end{array}$ & 강도(완전 휴식) & 개선 \\
\hline & $\begin{array}{l}\text { Mujika et } \\
\text { al.(1996) }\end{array}$ & $\begin{array}{c}\text { 유지, } \\
\text { (훈련량감소: } \\
\text { 50-75\%) }\end{array}$ & $\begin{array}{l}\text { 유지, } \\
\text { 또는 개선 }\end{array}$ \\
\hline & $\begin{array}{l}\text { Bosquet et } \\
\text { al.(2007) }\end{array}$ & 감소 & 감소 \\
\hline & $\begin{array}{l}\text { Hickson et } \\
\text { al.(1985) }\end{array}$ & 감소(66\%) & 감소 \\
\hline \multirow{5}{*}{$\begin{array}{l}\text { 트레이닝 } \\
\text { 훈련량 }\end{array}$} & $\begin{array}{l}\text { Mujika et } \\
\text { al.(2000) }\end{array}$ & 감소 & $\begin{array}{c}\text { 유지, } \\
\text { 또는 개선 }\end{array}$ \\
\hline & $\begin{array}{l}\text { Hickson et } \\
\text { al.(1985) }\end{array}$ & 감소(33-66\%) & 유지 \\
\hline & $\begin{array}{l}\text { Shepley et } \\
\text { al.(1992) }\end{array}$ & 감소(41-60\%) & 개선 \\
\hline & $\begin{array}{l}\text { Bosquet et } \\
\text { al.(2007) }\end{array}$ & 감소( $20 \%)$ & 유지 \\
\hline & $\begin{array}{l}\text { Naery et } \\
\text { al.(2003) }\end{array}$ & 감소(50-90\%) & 개선 \\
\hline \multirow{4}{*}{$\begin{array}{l}\text { 트레이닝 } \\
\text { 빈도 }\end{array}$} & $\begin{array}{l}\text { Johnes et } \\
\text { al(1992) }\end{array}$ & 감소(50\%) & 개선 \\
\hline & $\begin{array}{l}\text { Dressendorfer } \\
\text { et al.(2002) }\end{array}$ & 감소(50\%) & 개선 \\
\hline & $\begin{array}{c}\text { Mujika \& } \\
\text { Padilla(2003) }\end{array}$ & 감소(30-50\%) & $\begin{array}{c}\text { 개선(보통선수 } \\
\text { ) }\end{array}$ \\
\hline & $\begin{array}{c}\text { Mujika \& } \\
\text { Padilla(2003) }\end{array}$ & 감소(20\%) & $\begin{array}{l}\text { 더 큰 효과 } \\
\text { (우수선수) }\end{array}$ \\
\hline
\end{tabular}




\section{트레이닝 강도(Training Intensity)}

훈련 세션 동안 운동선수는 $\mathrm{VO} 2 \max$ 의 저강도에서 고 강까지 훈련하는 테이퍼링 국면에서는 훈련 강도를 조절 하는 다양한 방법이 있다(Shepley et al., 1992). Shepley et al. (1992)은 고도로 훈련된 선수를 대상으 로 고강도 그룹(초기 훈련보다 더 높은 강도 훈련), 저강 도 그룹, 그리고 8주 강렬한 훈련 후 완전휴식 그룹에서 이와 같은 3 가지의 7 일 테이퍼링 방법을 비교했다. 저강 도 완전휴식 집단은 이들 변인에서 개선 효과가 적은 것 으로 드러났다. 이와 같은 3가지의 테이퍼링 방법에서 모 두 훈련량이 감소하였으며, 이러한 바람직한 적응에 기여 했을 가능성이 있다. 또한, Mujika et al. (1996; 2003) 연구진은 훈련량을 $75 \%$ 까지 낮추면서 동시에 고강도로 훈련을 유지하는 것이 훈련량을 $50 \%$ 까지 줄이면서 저강 도 훈련하는 것과 비교할 때, 특히 혈액학적 측정치와 테 스토스테론 수준에서 우수한 생리학적 적응력을 보인다 는 결론을 내렸다. 반면에, 흥미롭게도 고강도 그룹은 테 이퍼링 이후에도 경기력을 유지하거나 증가시켰는데, 이 방법은 경기력에 대한 많은 생리적 적응 마커(markers) 에서 확인할 수 있었다. 혈액량 및 적혈구 수 증가, 안정 시 글리코겐 농도 및 구연산 효소 활성화, 최대 수의적 수 축, 피로 시간 등에서 확인되었다.

다른 주목할 만한 연구에서는 테이퍼링 국면 중 훈련 강도를 감소시킨 결과 경기력이 현저하게 감소한 것이 명 백하게 드러나면서 훈련 강도 유지의 중요성은 더욱 두드 러지게 확인되었다(Bosquet et al., 2007). 또 다른 추가 연구에서 유사 연구방법에서 트레이닝 강도를 조절한 연 구에서 최적의 생리학적 적응을 달성하기 위해서는 훈련 강도를 높이거나 유지해야 한다는 연구 결과를 뒷받침한 다(Hickson et al 1985; Houmard et al., 1994). 테이 퍼링 국면에서 훈련 강도 감소에 의한 부정적 효과는 훈 련 강도를 최대 $66 \%$ 까지 감소시킨 후, 특히 에어로빅 파 워가 현저하게 감소한다는 연구 결과와 일치한다 (Hickson et al., 1985), 종합적으로, 이러한 연구들은 테이퍼링 국면에서 훈련 강도를 유지해야 한다는 것을 시 사한다.

\section{트레이닝 훈련량(Training Volume)}

한 문헌연구는 테이퍼링 효과를 높이고, 동시에 선수 의 생리학적 프로파일을 더 발전시키거나 유지하기 위해 사합전에 이르기까지 훈련량의 감소가 중요하다는 점을 시사하고 있다(Johns et al., 1992; Mujika et al., 2000). 많은 연구들은 수영, 달리기, 사이클, 트라이애슬 론, 저항성 훈련에서 바람직한 적응결과를 유도하기 위 해, 또는 최소한의 경기력수준을 유지하기 위해서는 훈련 량 감소의 필요성을 반복적으로 입증해왔다(Pyne, 2002; Johns et al., 1992; Mujika et al., 2000; Neary et al., 2003; Neary et al., 1992; Gibala et al., 1994; Zarkadas et al., 1995) .

Hickson et al. (1985) 연구는 주기화로 구조화된 훈련프로그램 중 훈련량과 테이퍼링 사이의 관련성을 발 견한 최초의 연구 중 하나이다. 훈련 시간이 $33 \%$ 혹은 $66 \%$ 까지 감소되었을 때, $\mathrm{VO} 2 \mathrm{max}$ 와 다른 생리학적 능 력이 향후 15 주 동안 유지되었다는 점에 주목했다. 이러 한 결과는 Shepley et al. (1992)의 조사로 확인되었다. 훈련량이 현저히 줄어들었을 때라도, 훈련강도가 높게 유 지될수록 더욱 높은 생리적 적응결과들이 관찰되었음이 보고되었다(Shepley et al., 1992). 그러나 일부 제한된 문헌은 팀 기반 스포츠에서의 향상을 계량화하는 데 기여 하였다. 이러한 연구들은 테이퍼링 국면 동안 훈련량의 $50 ~ 90 \%$ 까지 감소했다고 일관되게 보고했으며, 이는 경 기 전에 운동선수를 충분히 회복시키기 위해 필요하다는 것을 시사했다. 또한 테이퍼링 국면 동안 선수가 각 종목 의 선수들에 따라 훈련량의 $41 \%$ 에서 $60 \%$ 까지 감소에 따라 테이퍼링 국면 이후 가장 많은 경기력 향상을 발견 했다. Bosquet et al. (2007)의 연구에서도 시합까지 이 어지는 과정에서 최적의 경기력을 달성하기 위해서는 훈 련량을 줄이는 것이 필요하다는 제시하였다. 테이퍼링 중 훈련량이 $20 \%$ 이하까지 줄어들면 경기력은 저하될 수 있 는 것과 마찬가지로, 훈련량이 $60 \%$ 이상 감소하면 그것 은 훈련중지 효과를 유발하는 것과 같다는 점에 주목했다 (Bosquet et al., 2007).

본 연구에서는, 팀 기반 스포츠종목에서는 어떠한 연 구 결과도 제시되지 않았다. 이는 아직까지 팀 전체를 대 상으로 훈련 중 테이퍼링이 경기력 향상을 위해 계량화하 
는데 기여할 수 있는 연구가 다수 발표 되었으나, 팀 전체 에 훈련량 계량화를 통해 개개인의 경기력을 최상으로 끌 어 올릴 수 있는가에 대한 과학적 제시를 위해서 더 많은 후속연구가 필요하다.

\section{트레이닝 빈도(Training Frequency)}

테이퍼링 국면을 계획할 때 훈련 빈도를 조절하는 것 은 복잡한 접근방식으로 보인다. 몇몇 연구자들은 훈련 빈도를 줄이면 경기력이 향상되지 않을 수 있다고 제안하 고(Bosquet et al., 2007; Mujika \& Padilla, 2003), 반면 다른 연구자들은 경기력을 유지하거나 향상시키기 위해 훈련 빈도를 줄이는 것이 유익할 수 있다고 결론지 었다(Houmard et al., 1994; Johns et al., 1992). Johns et al. (1992)의 연구에 따르면 테이퍼링 국면 중 훈련 빈도를 $50 \%$ 까지 줄임으로써 수영선수에서 생리학 적 지표 (markers)의 개선을 보고했다. 마찬가지로, 사이 클링 선수들은 테이퍼링 국면 동안 훈련 빈도를 $50 \%$ 까지 감소시킨 후 경기력이 개선된 것을 보여주었다 (Dressendorfer et al., 2002). 반면에, Bosquet et al. (2007)의 메타분석을 실시한 연구에서 훈련 빈도를 줄인 결과 경기력은 개선되지 않았다고 밝혔다. 그러나 선수 훈련 상태는 선수가 최적의 경기력을 달성하기 위해, Mujika \& Padilla, (2003)의 연구에서는 테이퍼링 국면 중 특정 기간(week) 동안에 어느 정도의 빈도로 훈련해 야 하는지가 경기력 향상에 중요한 역할을 하는 것으로 보인다고 하였다.

일반적으로, 고도로 훈련된 운동선수는 평소 정상적인 훈련 과정의 결과처럼, 그리고 "경기감각 상실(loss of feel)"이 완화된 것처럼, 테이퍼링 국면 중 어떤 경기력 향상도 보이지 않는다. 이는 고도로 훈련된 선수들이 테 이퍼 국면 동안 훈련 빈도를 대폭 줄이는 데 초점을 맞추 지 말아야 함을 시사한다. 또한, 대부분의 연구는 운동선 수들이 훈련 빈도를 약 30 50\%까지 줄임으로써 경기력 에 향상을 얻을 수 있다는 것을 보여주었고, 특히 잘 훈련 된 운동선수들은 더욱 큰 경기력 향상을 보였고, 훈련 빈 도를 불과 $20 \%$ 이하로 줄이는 것이 가장 효과적인 것으 로 나타났다(Mujika \& Padilla, 2003). 이는 특정 선수 에서 기술력과 기술 의존도가 높은 스포츠 경기력을 유지
해야 하는 필요성 때문일 수 있으며, 특히 수영선수의 경 우에 가장 두드러지게 차이를 보였다(Mujika \& Padilla, 2003).

그러나 보통수준으로 훈련된 선수들의 경우, 훈련 빈도 는 테이퍼 전체 국면에서 30 50\%까지 감소했을 때 보다 더 효과적인 것으로 보였으며(Mujika \& Padilla, 2003), 훈련 빈도를 최소로 줄여야 하는 선수에게는 신체적 관리, 전술적, 기술적 준비에 보다 더 중점을 두어야 한다.

\section{테이퍼의 지속기간(Duration of the Taper)}

훈련계획 수립 시 테이퍼의 지속기간을 설정하기는 다 소 어렵지만, 여전히 테이퍼의 기간은 테이퍼의 효과에 영향을 미치는 가장 중요한 요소로 남아 있다. 과학적 연 구결과에 의하면, 테이퍼링 기간을 연장할 수 있는 최적 의 기간(days)은 주어진 환경에 의해 폭넓은 기간의 권 고안을 제시하고 있다. 근력이 잘 훈련된 선수와 수영 선 수도 각각 10일, 10 35일 테이퍼링 기간을 통해 긍정적 인 성과를 보였다(Gibala et al., 1994; Johns et al., 1992; Pyne, 2002). 한편, 사이클 선수와 트라이애슬 론 선수들은 4 14일의 테이퍼 기간 이후 생리적, 심리 적, 그리고 경기 적응력이 뚜렷했지만(Kubukeli et al., 2002; Neary et al., 1992; Zarkadas et al., 1995), Mujika et al. (2000)과 Shepley et al.(1992)의 연구 에서는 보다 짧은 6 7일의 테이퍼링 기간 동안 개선되 었음을 보고했다. 종합해보면, 앞에서 언급한 연구 결과 들은 스포츠의 종목에 따라 테이퍼링의 지속기간에 약간 의 영향을 받은 수 있다는 것을 시사한다. 선행 연구를 종 합해보면 〈Table 2)과 같이, 테이퍼링 지속기간은 다양 하게 나타나고 있다는 점을 고려할 때, 시합이나 시합 전 중요한 시점 (마일스톤-milestone)에서도 스포츠 과학자 와 코치들은 장기간의 테이퍼링을 적용함으로써 선수로 하여금 훈련중단(detraining)의 원인이 되기도 한다. 동 시에 회복력을 과대평가하여 결과적으로 경기력을 저해하 는 원인이 되고 있음을 주의해야 하며(Kubukeli et al., 2002), 테이퍼링 기간은 테이퍼링 국면 동안 감소된 훈련 량에 따라 테이퍼링 지속 기간이 크게 좌우될 것이라고 사 료된다(Thomas \& Busso, 2005). Bosquet et al. (2007)의 메타분석 결과 경기력향상을 위한 테이퍼 적정 
기간은 일반적으로 8-14일이 일반적이며, 이는 특히 수 영, 달리기, 사이클 전반에 걸쳐 경기력을 향상시키기 위 한 테이퍼의 최적기간으로 나타났다. 만약 훈련량이 크게 감소하면, 테이퍼링의 지속기간이 보다 짧아야 하며, 그 반대의 경우에도 생리적 적응력을 유지하거나 더 발전시

Table 2. 테이퍼링이 엘리트 지구력 선수의 경기력에 미 치는 연구결과

\begin{tabular}{|c|c|c|c|c|c|}
\hline 구분 & $\begin{array}{l}\text { 저자 } \\
\text { (연도) }\end{array}$ & $\begin{array}{l}\text { 연구 } \\
\text { 대상 }\end{array}$ & $\begin{array}{c}\text { 테이퍼 } \\
\text { 기간 } \\
\text { (일) }\end{array}$ & $\begin{array}{c}\text { 측정변인 } \\
\text { (상황) }\end{array}$ & $\begin{array}{l}\text { 상승 } \\
\text { 효과 } \\
(\%)\end{array}$ \\
\hline 1 & $\begin{array}{l}\text { Costill et } \\
\text { al.(1991) }\end{array}$ & $\begin{array}{l}\text { swimmer } \\
\text { s }\end{array}$ & $14-21$ & 실제 시합 & 3.2 \\
\hline 2 & $\begin{array}{l}\text { Shepley et } \\
\text { al.(1992) }\end{array}$ & runners & 7 & GXT 시간 & $6-22$ \\
\hline 3 & $\begin{array}{l}\text { Martin et } \\
\text { al.(1994) }\end{array}$ & cyclists & 14 & GXT 시간 & 8.0 \\
\hline 4 & $\begin{array}{l}\text { Mujika et } \\
\text { al.(1996) }\end{array}$ & $\begin{array}{l}\text { swimmer } \\
\text { s }\end{array}$ & 28 & $\begin{array}{c}100-200 \mathrm{~m} \\
\text { 시합 }\end{array}$ & $0.4-4.9$ \\
\hline 5 & $\begin{array}{l}\text { Taylor et } \\
\text { al.(1997) }\end{array}$ & $\begin{array}{l}\text { swimmer } \\
\text { s }\end{array}$ & $\begin{array}{c}\text { no } \\
\text { reported }\end{array}$ & 실제 시합 & 1.3 \\
\hline 6 & $\begin{array}{l}\text { Hooper et } \\
\text { al.(1998) }\end{array}$ & $\begin{array}{c}\text { swimmer } \\
\mathrm{s}\end{array}$ & 14 & 실제 시합 & 없음 \\
\hline 7 & $\begin{array}{l}\text { Bonifazi et } \\
\text { al.(2000) }\end{array}$ & $\begin{array}{c}\text { swimmer } \\
\mathrm{s}\end{array}$ & $14-21$ & $\begin{array}{c}100-400 \mathrm{~m} \\
\text { 시합 }\end{array}$ & $1.5-2.1$ \\
\hline 8 & $\begin{array}{l}\text { Martin \& } \\
\text { Anderson } \\
\text { (2000) }\end{array}$ & cyclists & 7 & GXT 시간 & 6.0 \\
\hline 9 & $\begin{array}{l}\text { Mujika et } \\
\text { al.(2000) }\end{array}$ & runners & 6 & $800 \mathrm{~m}$ 시합 & 없음 \\
\hline 10 & $\begin{array}{c}\text { Smith(2000 } \\
\text { ) }\end{array}$ & rowers & 7 & $\begin{array}{c}500 \mathrm{~m} \\
\text { 모의시합 }\end{array}$ & 없음 \\
\hline 11 & $\begin{array}{l}\text { Steinacker } \\
\text { et al. (2000) }\end{array}$ & rowers & 7 & $\begin{array}{l}2000 \mathrm{~m} \\
\text { 모의시합 }\end{array}$ & 6.3 \\
\hline 12 & $\begin{array}{l}\text { Trappe et } \\
\text { al.(2001) }\end{array}$ & $\begin{array}{l}\text { swimmer } \\
\text { s }\end{array}$ & 21 & 실제 시합 & $3.0-4.7$ \\
\hline 13 & $\begin{array}{l}\text { Mujika et } \\
\text { al.(2002) }\end{array}$ & runners & 6 & $800 \mathrm{~m}$ 시합 & $0.4-1.9$ \\
\hline 14 & $\begin{array}{l}\text { Maestu et } \\
\text { al.(2003) }\end{array}$ & rowers & 14 & $\begin{array}{c}2000 \mathrm{~m} \\
\text { 모의시합 }\end{array}$ & 없음 \\
\hline 15 & $\begin{array}{l}\text { Trinity et } \\
\text { al.(2006) }\end{array}$ & $\begin{array}{l}\text { swimmer } \\
\text { s }\end{array}$ & 21 & $\begin{array}{c}\text { 50-1500m } \\
\text { 시합 }\end{array}$ & 4.5 \\
\hline 16 & $\begin{array}{l}\text { Coutts et } \\
\text { al.(2007) }\end{array}$ & $\begin{array}{c}\text { triathlete } \\
\mathrm{s}\end{array}$ & 14 & $3 \mathrm{~km}$ 달리기 & 3.9 \\
\hline 17 & $\begin{array}{l}\text { Papoti et } \\
\text { al.(2007) }\end{array}$ & $\begin{array}{l}\text { swimmer } \\
\text { s }\end{array}$ & 11 & $200 \mathrm{~m}$ 시합 & 1.6 \\
\hline 18 & $\begin{array}{l}\text { Vollaard et } \\
\text { al.(2006) }\end{array}$ & $\begin{array}{c}\text { triathlete } \\
\mathrm{s}\end{array}$ & 7 & $\begin{array}{c}15 \mathrm{~m} \\
\text { 모의시합 }\end{array}$ & 4.9 \\
\hline
\end{tabular}

키기 위해서는 전체 훈련량은 충분해야 한다. 모든 선수의 테이퍼링 지속기간은 훈련 부하 감소에 대한 생리적, 심리 적 반응에 따라 개별화되어야 하며, 이는 각 운동선수를 세심하게 이해함으로써 가장 효과적으로 응용할 수 있다.

\section{테이퍼 유형(Type of Taper)}

점증적 (progressive) 또는 비점증적 (non-progressive) 테이퍼링 방법에 대한 연구에서 광범위하게 조사한 결과 크게 2가지 유형의 테이퍼링이 있다(Bompa \& Haff, 2009). 이름에서 알 수 있듯이, 점증적 테이퍼링은 훈련 부하량의 점진적인 감소를 활용하는 반면, 비점증적 테이 퍼링은 스텝 테이퍼(step taper)로 이미 알려져 있으며, 테이퍼링 전체 기간을 통해서 훈련 부하량의 즉각적인 감 소를 채택하여 안정적인 상태를 유지하게 된다. 점증적 테이퍼링은 훈련 부하량이 점진적으로 감소하는 방법으 로 3 가지 형태가 있는데, 이는 〈Figure 3〉과 같이 (1)선 형 (linear), (2)느린 지수형 (slow exponential), (3) 빠 른 지수형 (fast exponential)의 테이퍼링 형태이다 (Bosquet et al., 2007; Mujika \& Padilla, 2003). 선 형 테이퍼링은 훈련 부하량이 느린 지수형 혹은 빠른 지 수형 테이퍼링보다 훨씬 큰 규모로 점증적으로 훈련 부하 량을 감소시키는 방법인 반면, 느린 지수형 테이퍼는 빠 른 지수형 테이퍼보다는 더 많은 훈련 부하량을 실시하는 방법이며, 따라서 빠른 지수형 테이퍼는 테이퍼링 전체 기간 동안 훈련 부하량을 점점 더 빠르고 더 많이 감소시 키는 방법이다(Mujika \& Padilla., 2003; Zarkadas et al., 1995).

그 동안 스텝(step) 테이퍼링은 많은 연구에서 테이퍼 링 국면 이후 경기 적응력 향상을 통해서 아주 효과적이 었다고 하더라도(Hickson et al., 1985; Mujika \& Padilla, 2003), 점증적인 테이퍼링에서 경기력향상에 보다 더 성공적인 것으로 나타났다(Banister et al., 1999; Bosquet et al., 2007; Zarkadas et al., 1995). 이는 스텝 테이퍼링 방법이 테이퍼 기간 동안 경기력수준 을 유지하기 위해 제공하는 훈련 자극의 부족 때문으로 설명될 수 있으며 결과적으로 경기력은 감소한 것으로 나 타났다(Banister et al.,1999).

Mujika \& Padilla (2003)의 연구는 스텝 테이퍼링은 
$1.2 \sim 1.5 \%$ 의 경기력을 올릴 수 있는 잠재력이 있는 반 면, 점증적 테이퍼링은 최대 4 6\%의 경기력 향상을 보 였다. 보최근 연구 된 Lacey et al., (2015)에 의하면, 테 이퍼링 초기에는 향상이 발견되었고, 테이퍼링이 계속되 면서 경기력은 저하되었으며, 이는 이러한 스텝형태의 테 이퍼링은 보다 더 짧은 기간 동안의 테이퍼링 보다 더 유 효할 수 있음을 시사한다. 테이퍼링 21일 동안의 스텝 테 이퍼링 국면에서 프로 럭비리그 선수들에게 최대 속도, 힘-속도 간 프로필, 또는 전체적인 경기력에서 어떠한 경 기력 향상도 보이지 않았다고 보고했다(De Lacey et al., 2014). 반면 Sanchez et al. (2013) 연구진은 점진적인 선형 테이퍼링이 경기력 향상에 효과적이지만 스텝 테이 퍼링과 비교해 훈련 부하가 높았기 때문에 테이퍼링의 지 속시간을 연장함으로써 개선될 수 있음을 입증했다.

전반적으로 저자들은 비점증적 테이퍼링보다는 점증 적 테이퍼링 방법이, 보다 구체적으로는 훈련 부하량의 빠른 지수적 감소를 권장히며, 느린 지수적 감소 프로토 콜이 $2.4 \%, 3.8 \%$ 까지 경기력이 향상되지만, 반면에 빠 른 지수적 감소 방식은 $6.3 \%, 7.9 \%$ 까지 향상된 경기력 을 보였다는 결론을 내렸다(Banister et al., 1999; Zarkadas et al., 1995) 이는 부분적으로 느린 지수적 감소의 테이퍼링 방법보다는 훈련량이 보다 적은 빠른 지 수 테이퍼링 방법 때문일 수 있으며, 결국 선수가 긍정적 인 영향과 부정적인 영향 사이의 적절한 균형을 통해 최 적의 적응력(경기력)을 달성하기 위해서는 추가적인 회 복이 확보되어야 한다(Mujika \& Padilla, 2003).

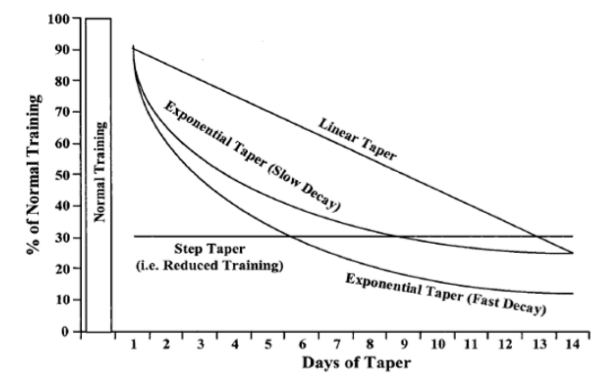

Fig. 3. 선형 테이퍼, 부하량 감량이 느린 경우의 지수형 테이퍼, 부하량 감량이 빠른 경우의 지수형 테이퍼, 스텝 테이퍼

(Mujika \& Padilla S., 2003; Adam J. Veli, 2017).

\section{결론 및 제언}

문헌연구에 근거해 볼 때, 경쟁까지 이어지는 테이퍼링 방식은 절차의 적절한 이행에 따라 운동선수를 위한 이상 적인 효과성을 입증했다. 훈련 강도, 훈련량, 훈련빈도, 테이퍼링 지속시간 및 테이퍼의 종류를 잘 조정함으로써, 적절한 준비과정이 생리적, 심리적 효과를 달성하고, 다시 중요 시합까지 이어지는 과정에서 경기력을 최적화하는 것으로 나타났으며, 이를 정리하면 다음과 같다.

첫째, 테이퍼링 기간 중 트레이닝 강도는 유지한다.

둘째, 테이퍼링 기간 중 트레이닝 부하량은 41-60\%까 지 감소한다.

섯째, 테이퍼링 기간 중 트레이닝 빈도는, 고도로 훈련 된 선수는 유지하고, 보통 수준의 선수는 감소하는 것이 좋다.

넷째, 테이퍼링 기간은 통상 8-14일 정도를 권장한다.

그럼에도 불구하고, 이들 선행연구들의 테이퍼링 효과 및 방법과 관련하여 제언을 덧붙인다면, 트레이닝 강도 는 테이퍼링 기간 동안 유지되어야 한다. 반대로, 트레이 닝 강도가 감소된다면, 트레이닝에 의한 적응력이 중요 시합에서 적정수준 이하의 경기력으로 떨어질 수도 있기 때문이다. 테이퍼링 기간 중 트레이닝 부하량 감소는 트 레이닝 량(training volume)을 감소시키는 방법으로 계 획되어야한다. 이러한 트레이닝 량의 감소는 통상 트레이 닝 프로그램 구성요소들에 의해 영향을 받게 된다. 트레 이닝 빈도를 평가하는 연구결과에 따르면, 빈도를 감소시 켰을 경우, 느낌 (feel)이 더 요구되는 스포츠, 즉 보다 더 테크닉에 의존하는(technique-dependent) 스포츠에서 는 경기력 손실 위험성이 클 수도 있다.테이퍼링 지속 기 간이 짧게는 4 일, 길게는 5 주 후에도 생리적 적응력과 경 기 능력에서 유익한 효과를 발표하였다. 이는 대부분 선 수들마다의 체력과 피로 수준에 따라 달라질 수 있기 때 문이다.

향후 테이퍼링 실행에 대한 보다 더 정밀하고 효과적 인 결과를 도출하기 위해서는, 경기력 수준이 다양한 선 수와 다양한 스포츠 영역에서 수 많은 시행착오와 수년간 의 경험이 필요할 수 있으므로 테이퍼링 방법에 따른 생 
리학적, 심리적 효과를 병행하여 연구할 뿐 만 아니라 테 이퍼링 절차에 따른 개인 스포츠와 팀 스포츠에 대한 실 질적인 차이도 연구할 필요가 있다고 제언하였다.

\section{참고문헌}

Adam, J.V., (2017). Effectiveness of tapering for competition: A brief review. Journal of Australian Strength and Conditioning. 25(1): 9.

André, B., Anton, R., \& Yu, J.G. (2013). Effects and Mechanisms of Tapering in Maximizing Muscular Power. Sport and Art. 1(1), 18-23.

Banister, E.W., Carter, J.B, \& Zarkadas, P.C. (1999). Training theory and taper: validation in triathlon athletes. European journal of applied physiology and occupational physiology 79: 182-191.

Bompa, T.O., \& Carrera, M.C. (2005). Periodization Training for Sports. Human Kinetics. 89-95.

Bompa, T.O., \& Half, G.G. (2009). Periodization-Edition: Theory Methodology of Training(5th Revised edition). Human Kinetics. 153-172.

Bonifazi, M., Sardella, F., \& Luppo, C. (2000). Preparatory versus main competitions: differences in performances, lactate responses and pre-competition plasma cortisol concentrations in elite male swimmers. European Journal of Applied Physiology, 82, 368-373.

Bosquet, L., Montpetit, J., Arvisais, D., Mujika, I. (2007). Effects of tapering on performance: a meta-analysis. Medicine and science in sports and exercise. 39, 1358.

Cosill, D. L., Thomas, R. Robergs, R. A., Pascoe, D., Lambert, C., Barr, S., \& Fink, W. J. (1991). Adaptations to swimming training: influence of training volume. Medicine and Science in Sports and Exercise, 23(3), 371-377.

Coutts, A., reaburn, P., Piva, T. J., \& Murphy, A. (2007). Changes in selected biochemical, muscular strength, power, and enfurance measures during deliberate overreaching and tapering in rugby league players. International Journal of Sports Medicine, 28, 116-124.

De Lacey, J., Brughelli, M., McGuigan, M., Hansen, K., Samozino, P., Morin, J.B. (2014). The Effects of Tapering on Power-Force-Velocity Profiling and Jump Performance in Professional Rugby League Players. The Journal of Strength \& Conditioning Research, 28, 3567-3570.

Dressendorfer, R.H, Petersen, S.R, Lovshin, S., Keen C.L.(2002). Mineral metabolism in male cyclists during high-intensity endurance training. International journal of sport nutrition and exercise metabolism, 12, 63-72.

Gibala, M..J., MacDougall, J..D., Sale, D.G.(1994). The effects of tapering on strength performance in trained athletes. International journal of sports medicine, 15, 492-497.

Hickson, R.C., Foster, C., Pollock, M..L., Galassi, T..M., Rich, S. (1985). Reduced training intensities and loss of aerobic power, endurance, and cardiac growth. Journal of Applied Physiology, 58, 492-499.

Hoffman, J. (2014). Physiological Aspects of Sport Training and Performance. Human Kinetics, 207-236.

Hopper S. L., Mackinnon L. T., \& Ginn E., M. (1998). Effects of three tapering techniques on the performance, forces and psychometric measures of competitive swimmer. European Jounal of Applied Physiology and Occupational Physiology, 78, 258-263.

Houmard, J.A, Scott, B.K., Justice, C.L., Chenier, T.C. (1994). The effects of taper on performance in distance runners. Medicine and science in sports and exercise, 26, 624-631.

Jang, G.T., Lee, J.S. (2007). Sport Physiology for Coaches. Deahanmedi. 185-204.

Johns, R.A., Houmard, J.A., Kobe, R.W., Hortobágyi, T., Bruno, N.J., Wells, J.M., Shinebarger, M.H. (1992). Effects of taper on swim power, stroke distance, and performance. Medicine and science in sports and exercise, Oct(24), 1141-1146.

korean Society Of Exercise Physiology. (2018). Sports Training(5th). Life Science. 63-143.

Kubukeli, Z.N., Noakes, T.D., Dennis, S.C. (2002). Training techniques to improve endurance exercise performances. Sports Medicine, 32, 489-509.

Lee, B. D. (1998). Effects of a reduced training volume and frequency taper on performance and muscle glycogen of sprint swimmers. Ph.D. Dissertation, Myongji University.

Maestu, J., Jurimae, J., \& Jurimae, T. (2003). Hormonal reactions during heavy training stress and following tapering in highly trained male rowers. Hormone and Metabolic Research, 35(2), 109-113.

Martin, D. T., \& Andersen, M. B. (2000). Heart rate-perceived 
exertion relationship during training and taper. Journal of Sports Medicine and Physical Fitness. 40(3), 201-208.

Martin, D. T., Scifres, J. C., Zimmerman, S. D., \& Silkinson, J. G. (1994). Effect of interval training and a taper on cycling performance and isokinetic leg strength. International Journal of Sports Medicin, 15(8), 485-491.

Mujika, I. \& Padilla, S. (2000). Detraining: loss of training-induced physiological and performance adaptations. Part I. Sports Medicine, 30, 79-87.

Mujika, I. \& Padilla, S. (2003). Scientific bases for precompetition tapering strategies. Medicine \& Science in Sports \& Exercise. 35(7), 1182-1187.

Mujika, I. (2009). Tapering and Peaking for Optimal Performance. Human Kinetics. 69-87.

Mujika, I. (2011). Tapering for Triathlon Competition(review article). Journal of Human Sport \& Exercise, 6(2), 264-270.

Mujika, I., Busso, T., Lacoste, L., Barale, F., Geyssant, A., Chatard, J.C.(1996). Modeled responses to training and taper in competitive swimmers. Medicine and science in sports and exercise, 28, 251-258.

Mujika, I., Chatard, J. C., Busso, T., Geyssant, A., Barale, F., \& Lacoste, L. (1996). Use of swim-training profiles and performance data to enhance training effectiveness. Journal of Swimming Research, 11, 23-29.

Mujika, I., Goya, A., Padilla, S., Gorostiaga, E., \& Ibanez, J. (2000). Physiological responses to a 6-d taper in middle-distance reunners: influence of training intensity and volume. Medicine and Science in Sports and Exercise, 32, 511-517.

Mujika, I., Goya, A., Padilla, S., Grijalba, A., Gorostiaga, E., Ibañez, J. (2000). Physiological responses to a 6-d taper in middle-distance runners: influence of training intensity and volume. Medicine and science in sports and exercise. 32, 511-517.

Mujika, I., Goya, A., Ruiz, E., Grijalba, A., Santisteban, J., \& Padilla, S. (2000). Physiological and performance responses to a 6-day taper in middle-distance runner: influence of training frequency. International Journal of Sports Medicine, 23, 367-373.

Neary, J.P., Bhambhani, Y.N., McKenzie, D.C. (2003). Effects of different stepwise reduction taper protocols on cycling performance. Canadian journal of applied physiology, 28, 576-587.
Neary, J.P., Martin, T.P., Reid, D.C, Burnham, R., Quinney, H.A. (1992). The effects of a reduced exercise duration taper programme on performance and muscle enzymes of endurance cyclists. European journal of applied physiology and occupational physiology, 65, 30-36.

Papoti, M., Martins, L. E. B., \& Cunha, S. A., (2007). Effects of taper on swimming force and swimmer performance after an experimental ten-week training program. Journal of Strength and Conditioning Research, 21(2), 538-542.

Park, D.S., Jang, G.T. (2014). Effects of Taper on Performance and Fatigue level in Modern Pentathlonists. Korea Sport Society, 12(1), 251-263.

Pyne, D. (2002). Swimming performance changes during the final 3 weeks of training leading to the Sydney 2000 Olympic Games. International Journal of Sports Medicine, 23, 582-587.

Sanchez, A., Galbès, O., Fabre-Guery, F., Thomas, L., Douillard, A., Py, G., Busso, T., Candau, R.B. (2013). Modelling training response in elite female gymnasts and optimal strategies of overload training and taper. Journal of sports sciences, 31, 1510-1519.

Shepley, B., MacDougall, J. D., Cipriano, N., Sutton, J. R., Tarnopolsky, M. A., \& Coates, G. (1992). Physiological effects of tapering in highly trained athletes. Journal of Applied Physiology, 72, 706-711.

Shepley, B., MacDougall, J.D., Cipriano, N., Sutton, J.R., Tarnopolsky, M.A., Coates, G. (1992). Physiological effects of tapering in highly trained athletes. Journal of Applied Physiology, 72, 706-711.

Smith, H. K. (2000). Ergometer sprint performance and recovery with variations in training load in elite rowers. International Journal of Sports Medicin, 21, 573-578.

Steinacker, J. M., Lormes, W., Kellmann, M., Liu, Y., Reiienecker, S., Opitz-Fress, A., Baller, B., Guenther, K., Petersen, K. G., Kallus, K. W., Lehmann, M., \& Altenburg, D. (2000). training of junior rowers before world championships: effects on performance, mood wtate and selected hormonal and metabolic responses. Journal of Sports Medicine \& Physical Fitness, 40(4), 327-335.

Taylor, S. R., Rogers, G. G., \& Driver, H. S. (1997). Effects of training volume on sleep, psychological, and selected physiological profiles of elite female swimmers. Medicine and Science in Sports and Exercise, 92(5), 688-693. 
Thomas, L. Busso, T.A. (2005). Theoretical study of taper characteristics to optimize performance. Medicine and science in sports and exercise, 37, 1615-1621.

Trappe, S., Costill, D., \& Thomas, R. (2001). Effect of swim taper on whole muscle and single fiber contractile properties. Medicine and Science in Sports and Exercise, 33(1), 48-56.

Trinity, J. D., Pahnke, M. D., Resse, E. C., \& Coyle, E. F. (2006). Maximal mechanical power during a taper in elite swimmers. Medicine and Science in Sports and Exercise, 38(9), 1643-1649.

Veli, A.J.(2017). Effectivness of Tapering for Competition: A
Brief Review. Journal of Austrailian Strength and Conditioning, 25(1), 61-66.

Vollaard, N. B., Cooper, C. E., \& Shearman, J. P. (2006). Exercise-induced oxidative stress in overload training and tapering. Medicine and Science in Sports and Exercise, 38(7), 1335-1341.

Zarkadas, P.C., Carter, J.B., \& Banister, E.W. (1995). Modelling the effect of taper on performance, maximal oxygen uptake, and the anaerobic threshold in endurance triathletes, in: Modeling and Control of Ventilation. Springer. 179-186.

\title{
심폐지구력 선수의 주기화 훈련 모델에서 주시합기의 테이퍼 효과에 대한 문헌 고찰
}

\author{
윤재량 \\ 한국체육대학교 교수
}

〔목적〕 중요시합 전 경기력을 최적화하기 위한 방법으로 테이퍼 기간 동안 트레이닝 변인의 훈련강도 (intensity), 훈련량(volume), 훈련빈도(frequency), 테이퍼의 지속기간(duration), 그리고 테이퍼의 유 형(type)을 극대화하는 방법을 제시하는 것이다. 〔방법) 자료 수집은 1995년부터 2020년까지의 문헌을 대 상으로 H대학학술정보원에서 37편, KISS, SPORTDiscis를 통해 63편을 수집하였고, 이들 중 연구목적에 부합하는 논문 17 편과 연구자 본인이 소지하고 있는 문헌자료 5 편을 포함하여 총 22 편의 문헌분석을 실시하 였다. 〔결과〕 첫째, 테이퍼 기간 중 트레이닝 강도는 유지되어야 하며, 트레이닝 강도가 감소된다면, 중요 시 합에서 적정수준 이하의 경기력으로 떨어질 수도 있다. 둘째, 테이퍼 기간 중 트레이닝 부하량은 감소시키는 방법으로 계획되어야 하고, $41 \%-60 \%$ 까지 감소시켜야 한다. 섯째, 테이퍼 기간 중 트레이닝 빈도는 직전의 $30 \%-50 \%$ 까지 감소시켜야 하며, 반면에 고도로 훈련된 선수는 테이퍼 직전과 비슷한 수준으로 트레이닝 빈 도를 유지하는 것이 더 나을 수 있다. 넷째, 테이퍼 기간은 통상 8-14일 정도로 하되, 대부분 선수들은 2주의 테이퍼 기간이 도움이 되며, 이는 선수들마다의 체력과 피로 수준에 따라 달라질 수 있다. 〔결론) 테이퍼 기간 중 트레이닝 강도는 유지하고, 트레이닝 부하량 및 빈도는 감소하며, 테이퍼 기간은 2 주 정도로 하되, 파워 선수는 3-4일, 전신지구력 선수는 10-14일을 권장한다.

주요어: 테이퍼, 트레이닝 부하, 트레이닝 변인, 감소된 트레이닝, 경기력 